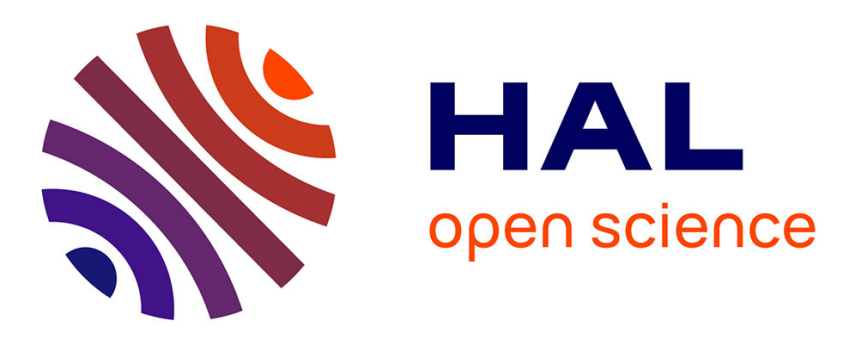

\title{
Exploration of the changing structure of cities: Challenges for temporal city models
}

Clémentine Périnaud, Georges Gay, Gilles Gesquière

\section{To cite this version:}

Clémentine Périnaud, Georges Gay, Gilles Gesquière. Exploration of the changing structure of cities: Challenges for temporal city models. International Congress on Digital Heritage - Theme 3 - Analysis And Interpretation, Sep 2015, Granada, Spain. 10.1109/DigitalHeritage.2015.7419455 . hal01386309

\section{HAL Id: hal-01386309 \\ https://hal.science/hal-01386309}

Submitted on 5 Nov 2016

HAL is a multi-disciplinary open access archive for the deposit and dissemination of scientific research documents, whether they are published or not. The documents may come from teaching and research institutions in France or abroad, or from public or private research centers.
L'archive ouverte pluridisciplinaire HAL, est destinée au dépôt et à la diffusion de documents scientifiques de niveau recherche, publiés ou non, émanant des établissements d'enseignement et de recherche français ou étrangers, des laboratoires publics ou privés. 


\section{EXPLORATION OF THE CHANGING STRUCTURE OF CITIES: CHALLENGES FOR TEMPORAL CITY MODELS}

\author{
Clémentine Périnaud, Georges Gay \\ EVS - Université Jean-Monnet \\ Saint-Etienne, France \\ clementine.perinaud@gmail.com
}

\author{
Gilles Gesquière \\ LIRIS - Université de Lyon \\ Lyon, France \\ gilles.gesquiere@liris.cnrs.fr
}

\begin{abstract}
The ALARIC project (Incremental Urban Change Research Project) is dedicated to the production of geo-historical information concerning two formerly industrial cities of the Lyon-Saint-Etienne region $\left(19^{\text {th }}\right.$ and $20^{\text {th }}$ century $)$. The exploration of the incremental nature of urban change implies identifying when certain historical processes took place, such as the shift from one-off to systematic construction and changes in urban planning strategies. Specifically, the case study investigates the emergence of local urban projects to compare the transformation processes of the urban fabric and to specify the pace of urban change. Historical records will be accessed through a virtual mapping environment based on the temporal reconstitution of cities in two dimensions, and sometimes for special cases in three dimensions. This paper presents methodological principles to reconstruct former cities in order to inquire urban change and requirements for effective sharing of hypotheses on the various states of the past urban landscape and associated transformation processes.
\end{abstract}

Index Terms - Urban change, geo-historical data, GIS-CAD workflow, standard, CityGML

\section{INTRODUCTION}

The exploration of the changing structure of cities is coupled with fruitful research using GIS-CAD workflows to reconstruct former cities at different stages of their evolution. Although few in number, these scientific projects constitute a solid field of study in geo-historical research, as exemplified in Europe by the Nantes 1900 project and the Virtual Leodium projet [1] [2] or the development of a 4D-GIS to study the medieval town of Cluny [3]. In the United States, temporal 3D-GIS, such as the reconstitution of Washington DC in 1815 [4] or the Sidney Timelap [5] has received an increased attention among researchers. Current developments of 4D GIS illustrated above are coupled with increasing attempts to renew historical visualization by the use of a wider variety of historical records and the introduction of temporal devices in order to navigate through the data [6].

In this context, the ALARIC project (Incremental Urban Change Research Project) is dedicated to the production of geo-historical information concerning two formerly industrial cities of the Lyon-Saint-Etienne region $\left(19^{\text {th }}\right.$ and $20^{\text {th }}$ century). Its objective is to contribute to the improvement of the possibilities to inquire urban transformation processes while considering not only a short period of history but a long-term perspective. Indeed, a longer-term perspective coupled with the reconstitution of urban development constitutes a pragmatic basis for investigating the complex and gradual renewal of town planning.

Large cities, for which extensive archival information is available, are priority sites for urban history, yet few studies have examined smaller one - especially French formerly industrial cities. Based on archival records that provide an overview of the entire city at a specific point of time, the spatialisation of sources, as various as technical plans, pictures or local discourses, enables us to inquire the existing or planned urbanity. The spatialisation of archival records refers to the fact to spatially represent the contents of a document collection on a mapping environment. Indeed, the disparity of the documents makes it necessary to organise them in a workflow to increase the efficiency of the production of geohistorical information. Archival records shall be accessed through a virtual mapping environment based on the temporal reconstitution of cities in two dimensions, but also in three dimensions: indeed the modelling of completed or planned projects provides a greater understanding of former urban landscapes, imagined futures and changes that actually occurred. The aim of accessing archival records is not only to promote their existence. Investigating their distribution in time and space and reconstruct former landscapes must help an understanding of urban transformation processes. 
Finally, this case study interrogates the possibility of a more widespread application, towards an enriched way to access historical sources and an effective sharing of hypotheses on the various states of the past urban landscape and involved transformation processes. However, in practice, the analysis and data exchange capabilities are generally abandoned because of the complexity of historical data [7] that are characterized by their uncertainty [8]. Thus, the paper describes remaining challenges to formalize our framework: the section 2 presents the geo-historical approach of the incremental urban change as a renewed understanding and inquiring of the pace of urban change. The third section illustrates requirements to provide an effective sharing of this knowledge and discusses implied methodological perspectives.

\section{THE INCREMENTAL URBAN CHANGE RESEARCH PROJECT}

\section{A. Formerly industrial cities as laboratory sites to inquire urban change}

An incremental urban change research underlines the idea that urban change is not random but responds to processes. Urbanisation can be regarded as the sum of many short-term constructions that are not consistent with each other, but a trajectory of change can also be identified over the long term. Indeed, urbanisation patterns, characterized by specific urban planning and urban forms, are historically situated. But the lack of a clean sweep from a pattern to another shall require us to analyse an urban production system that evolves over time by superimposing strong continuity and gradual change [9]. Urban fabric is of lasting nature. The study of the existing and planned city in a long-term perspective accounts for the progressive spread of renewed city planning. The research potential is related to the explanation of the latency between when a project appears and when it is fully institutionalised, or between the abandonment of a project and its reappearance a decade later. Local reactions will help understand different applications of projects over time. Thus, the city model becomes a laboratory for the study of local adaptation to urban change based on empirical and incremental identification of transformation processes (Fig 1).

The following comparison of the development of railways in Terrenoire and Givors provides an example of this approach to urban change. The selected two French sites were important cities of the first industrial revolution and are nowadays parts of periurban areas of Lyon and Saint-Etienne. Starting in the 1830 s, the first development of railways in Terrenoire, which followed the first industrial installations, started a process leading to a rapid integration of these urban forms as part of quotidian urban banality. Terms collected in archival records convey the idea of an urban model that would never be transformed. However, some of these railway facilities had an ephemeral existence compared to other urban entities (about forty years of operation from the 1880s to the 1920s). Since they were considered as a symbol of urban modernity, local authorities rejected any propositions for the redevelopment of the unused tramway facilities or unused industrial railways until the 1960's. In Givors on the contrary, the practical

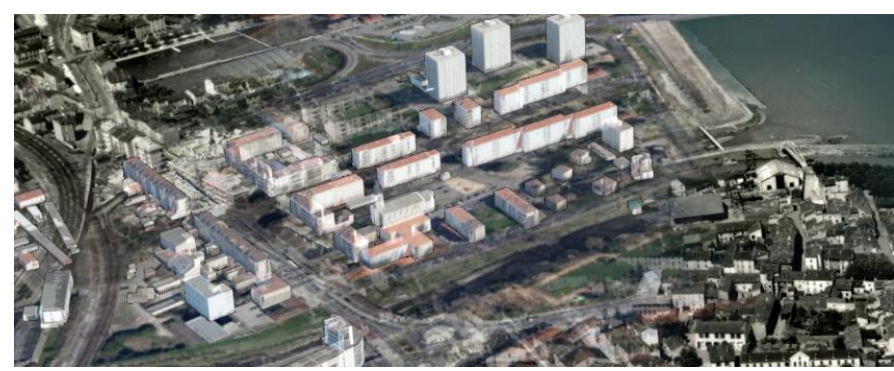

Fig 1. Superimposing of the actual landscape of Givors with a view of Givors in 1947.

development of railways in urban centers is coupled with opposing positions within one generation (from the 1830s to the 1850s): even though valued as a symbol of urban modernity, the proposed routes for railway lines were rejected by the local municipal council and citizens because of their negative impact on what were considered to be the pillars of a good urban development, such as the continuation of the Shipping on the river or the preventing of the destruction of other strategic areas. Heated negotiations took place over the future routes of the railways. Compromises which have been found explain the actual features of the city.

Such an approach allows us to become familiar with the pace of urban change, with the aim of perceiving current developments in light of these findings. What remains of past conceptions of urban development in the actual city and how long does one last in planning strategies?

\section{B. To inform contemporary urban change while mobilizing a wide range of historical records}

A wide range of historical records are collected to inform the existing or planned urbanity, in particular the technical plans drawn by the various jurisdictions responsible for urban regulations and the city council's minutes. This archival information proposes a first chronological approach to the main projects and local debates during the $19^{\text {th }}$ and $20^{\text {th }}$ centuries. Indeed their contents are related so that their distribution in space and time informs on transformation processes. Other historical records are explored on this first chronological basis, such as registered land plots, press articles, wind-up reports or architecture plans among others. They provide an increasing knowledge of local debates and private projects preceding or combined with the institutionalisation of a new type of town planning. An iconographic corpus provides additional guidance on the following of the existence and disappearance of urban entities, but also underlines what is symbolic of urbanity at historical moments. This constant crossing of various archival records allows us to inform, verify and investigate urban development.

The modeling, for instance of disappeared industrial installations or projects of infrastructures, is a way to integrate collected data to the mapping environment. But most of all, it enables us to understand the implications of imagined and completed changes. It shows a city produced by the negotiating of urban futures. 
Historical records used in the ALARIC project are fragments of urban scenes in time and space. In order to locate related projects, the spatialisation of records is guided by another type of archival sources providing an overview of every material objects of the city at a specific point in time (snapshot) with a precision equal to the referent view of the existing city in the present time - in this project, a 3D citymockup. Such reference documents are quite rare, one every fifty years or more, and mainly consist of high quality black-and-white aerial photographs and cadastral plans (Fig. 2). They constitute a reliable basis to follow urban development and localise other archival records that only cover a small area of urbanisation. Hence, we can't always know with extreme precision when a transformation process or a project took place. Their timelines are relative to the locating of archival records themselves.

Obviously, the disparity of these archival sources makes it necessary to organise them in a workflow to increase the efficiency and the ease of the production of geo-historical information. But the use of a temporal 3D-GIS confronts to the incompleteness and the vagueness of archival records. Thus, managing uncertainty in geo-historical data appears to be a real issue in the construction of temporal city models and invites researchers to question the quality of geo-historical data.

\section{METHODOLOGICAL PERSPECTIVES}

\section{A. Managing the lack and the imprecision of geo-historical data}

Major causes of uncertainties associated with geo-historical data based on records are properly identified [8] [10]. Lack of evidence is a first major issue. As described previously, the evidence that has survived is always partial and often very unevenly distributed in space and time. If the drawing of a project is available at a precise historical moment, the features of the urban environment might have changed, without the possibility of detection on the basis of the collected data. This simple fact symbolizes the impossibility of building a deterministic approach; it is illusory to try to reconstruct spacetime continuum of urban change in two dimensions and of course even more in three dimensions. Geometric features of urban entities increase the conjectural aspect of city models composed of built forms and a digital terrain model that might have change over time (for instance because of the disappearance of former waste heaps or the embankments of rivers).

Hence, the representation of existing but imprecise entities is another issue. If most of contemporary records are reliable, mainly because of the importance of technical plans, the use of textual sources often leads to deal with the lack of special precision ("next to...", "towards..."). A pragmatic approach of spatial uncertainty implies to manage the impact on the geometric visualisation of urban entities that depends on the level of imprecision of spatial information. Concerning temporal vagueness, most of the time, the creation date and termination date of an object is determined when it first occurs in records which is imprecise (a previous appearance or disappearance is always a possibility). Here again, a pragmatic

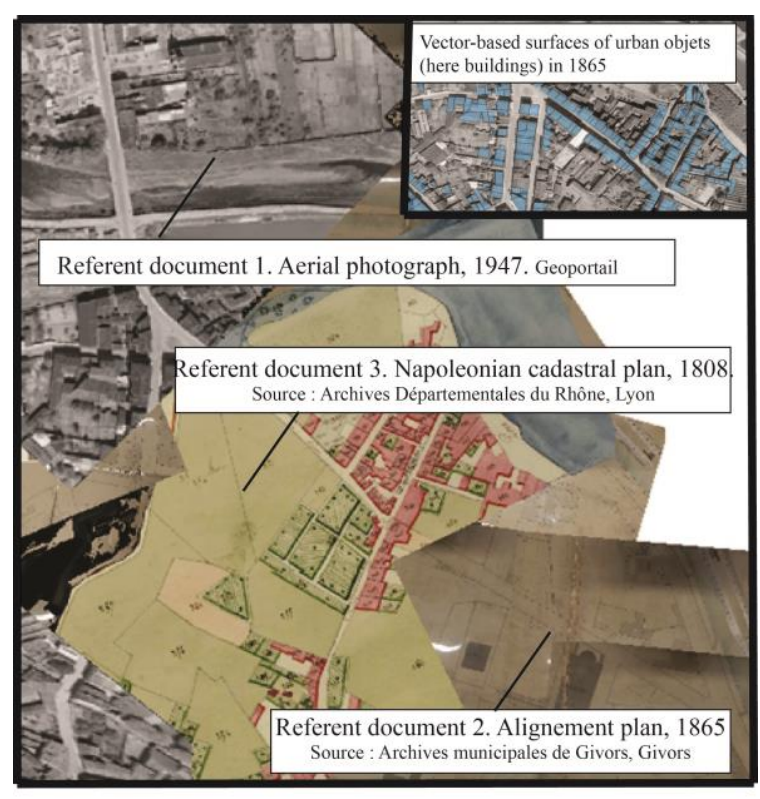

C. Périnaud - georeferenred and vectorised records in QGIS.

Fig. 2. Examples of reference documents used to have a precise view of the existing city on which other archival records are located.

approach would specify occasional attributes to inform the life cycle of entities when records give significant information (drawing, construction, modification in features or use) This attributes are linked to an existent and more generic object [11]. In general, spatial and temporal information shall be related to their archival source to efficiently trace it.

Semantics constitutes the greatest challenge. The vagueness of references (different names for a same entity) implies to manage a changing toponymy. Moreover, generic names of entities or urban projects are not consensual and question possibilities for managing it. Archival records provide their own semantics: terms used to designate a type of urban object or project change over time. A controlled semantics of object is required to facilitate the dissemination of geo-historical information but standards remain difficult to validate. For instance, in the CityGML standard, the code-lists of urban objects established by the Open Geospatial Consortium shall be validated and secondly efficiently related to an enriched semantics due to historical records. Other standardised languages, especially from the International Organisation for Standardisation responsible for a set of standards on geographic information, are currently tested in order to apply them on archaeological data [18].

\section{B. Requirements of a geo-historical standard}

This understanding of the status of uncertainty in temporal 3D-GIS [13] has consequences for the long-term viability of these mapping environments. Currently, conceptual challenges often lead to the autonomization of data environments. Indeed the complexity of the managing of uncertainty due to historical records explains the absence of a standardised language to qualify uncertainty in geo-historical data and also regarding the semantic organisation of such geo-historical information. Noted at the beginning of the 2000's [12], this problem 
remains unresolved [6]. In the Virtual Leonium project, sources are systematically linked to 3D objects [1], but there are still no examples of further standardised encoding of uncertainty due to archival records. More and more researchers claim the need for "a generalized approach for processing the data" collected from historical records [1] and a "need for standardization" [7] that shows a common will of an effective sharing of archeological and geo-historical information

New capabilities extend the use of CityGML standard, chosen in this used case as a neutral format to organise the data. The computer device enables a progressive and pragmatic encoding of geo-historical information, especially in time [14]. The 3D citymodel can address each included objet, according to need and new data: indeed, it consists on individual entities, such as generic objects due to a 3D mockup produced by the Urban Community of Lyon (tracks, roads, buildings and so on) or integrated one (CAD models) for which changes are recorded manually by the user and linked to objects. The computer device could be an answer to this erratic nature of geo-historical information due to records, but also responds to the need to distinguish imagined and existing objects. Thus, the standard enables a progressive increasing of the precision of geo-historical information, especially because of the possibility to manage temporal attributes of a city-object. Hence, the use case will test the possibility to produce a neutral exchange format gathering collected geo-historical information by proposing an access to archival records and related modelling of completed or planned projects.

\section{CONCLUSION}

These methodological principles support a pragmatic approach to the construction of temporal city models: geohistorical information due to historical records constitutes a basis confronting existent and planned urban projects in order to inquire urban transformation processes on a long-term perspective. Giving access to the content of heterogeneous records shall help a better understanding of urban change, for further improvement. On the basis of recognised standards, the description of the data organisation shall be made available, with the ultimate objective to provide an open data. The change of the way to produce geographical knowledge is exemplified by the increasing importance of the volunteered geographic information. But such a prospect requires a language that is simple and coherent to manage the vagueness of geo-historical information and to trace the origin of the data. The claim for a standardised model interrogates at least the possibility to share city models in order to collaboratively produce geo-historical information and understanding. Thus, ALARIC project is part of a larger set of research programs with clear principles but with hesitant exploration for twenty years. This can be due to the weakness of tools to visualise spatio-temporal information but also the remaining difficulty to control and share geohistorical data based on historical records.

\section{ACKNOWLEDGMENT}

This work was supported by the LABEX IMU (ANR-10LABX-0088) of Université de Lyon, within the program
"Investissements $d$ 'Avenir" (ANR-11-IDEX-0007) operated by the French National Research Agency (ANR). C. P. thanks the other members of her thesis committee, Sylvie Servigne, Stéphane Frioux, Christelle Morel-Journel, and Bernard Gauthier for their sympathetic help on the project.

\section{REFERENCES}

[1] B. Hervy, R. Billen, F. Laroche, C. Carré, M. Servières, M. Van Ruymbeke et al., "A generalized approach for historical mockup acquisition and data modeling: towards historically enriched 3D city models", in Usage, usability and utility of 3D city models, EDP Sciences, 2012.

[2] M. Pfeiffer, C. Carré, V. Delfosse, P. Hallot and R. Billen, "Virtual Leodium: from an historical 3D city scale model to an archaeological information system", ISPRS Annals of the Photogrammetry, Remote Sensing and spatial information sciences, vol. 2, Strasbourg, XXIV International CIPA Symposium, 2-6 septembre 2013.

[3] J.-F. Coulais, S. Faucher, A. Mazuir, Z. Petty, J. Rollier and G. Rollier, "Développement d'un SIG 4D pour la ville médiévale de Cluny », Archeologia e calcolatori, supplément 5, 2014, pp. 164-179.

[4] Bayley D. \& Schroader L., Visualizing Early Washington DC, Imaging Research Center, 2011 [On line].

[5] A. Wilson, 'Sydney timelap : integrating historical ressources using GIS', History and computing, vol. 13, 2003, pp. 45-68.

[6] I.N. Gregory, "Challenges and opportunities for Digital History", Frontiers in Digital Humanities, 1, 2014, pp. 1-2.

[7] B. De Roo, J. Bourgeois, P. De Mayer, A. C Addison and L. De Luca, "On the way to a 4D archaeological GIS: state of the art, future directions and need for standardization", Digital Heritage International Congress, 2013.

[8] B. Plewe, "The nature of Uncertainty in Historical Geographic information", Transaction in GIS, 6(4), 2002, pp. 431-456.

[9] Chesnau I. and Roncayolo M., L'ABCdaire de Marcel Roncayolo - introduction à une lecture de la ville, Infolio, 2011.

[10] G. Fusco and K. Emsellem, "L'Incertitude dans les sciences géographiques: spécificités et schémas d'appréhension', juin 2013, séminaire au sein du laboratoire ESPACE, UMR 7300.

[11] C. Stefani, L. De Luca, P. Véron and M. Florenzano, "Time indeterminacy and spatio-temporal building transformations: an approach for architectural heritage understanding”, International journal on interactive design and manufacturing, Vol. 4/1, Springer edition, 2010.

[12] I.N. Gregory, A Place in History: A guide to using GIS in historical research, Oxbow: Oxford, 2003.

[13] B. De Roo, N. Van de Wegue, J. Bourgeois, Ph. De Maeyer, "The temporal dimension in a 4D archaeological data model: applicability of the geoinformation standard", ISPRS Annals of the photogrammetry, Remote sensing and spatial information sciences, Vol. 2, ISPR $8^{\text {th }}$ 3DGeoInfo Conference and WG2 Workshop, Istanbul, 27-29 novembre 2013.

M. Morel and G. Gesquiere, "Managing temporal change of cities with CityGML", Eurographics Workshop on Urban Data Modelling and Visualisation, V. Tourre, G. Besuievsky ed. Strasbourg, 2014, pp. 37-42. 
